\title{
NOTE ON A CASE OF PIN-SWALLOWING.
}

\author{
Br JOHN KNOTT, M.A., M.D. Der., M.R.I.A.
}

[Read in the Section of Medicine, December 16, 1892.]

The pin, which I have the honour to exhibit to the Medical Section of the Royal Academy of Medicine in Ireland, was swallowed by a child of a little over three years old. The accident occurred about 6 a.m. on Oct. 16th last. The child, a bright and beautiful little girl, had been in the habit of exacting from her mother the duty of supplying her with morning tea at this early hour. She had also been affected with some bronchitis for a couple of days before, and her neck had been wrapped up with warm flannel for the night, which was secured in position by the pin in question. Having arranged the preparation of early morning tea, the mother returned to the room to find the flannel loosed from its place around her child's neck, and the pin gone. The child showed some slight choking symptoms, and her mother hurriedly gave her some tea to drink, when they disappeared.

The pin was swallowed on Sunday morning. I was out of town on that day and the following, and met the father of the child on Tuesday, who is a gentleman engaged in business in the city, and an old friend of mine. He took me at once to his residence to see his little girl, about whom both parents were naturally very anxious. I found that the child was coughing a great deal, and had been suffering from what her mother called "croupy" symptoms during the course of the few nights previous. She had accordingly received some hippo wine, and also got some aperient medicine. She had some diarrhoa on the day of my visit. There were no symptoms that could be referred to the presence of the pin 
in the alimentary canal. The parents were, of course, terribly anxious about their little one, and naturally wished to know whether anything could be done to remove the dangerous foreign body. I tried, as well as I could, to calm their apprehensions, but could not give them any encouragement in the way of active interference. I tuld them that I could not conscientiously recommend the operation of laparotomy, or even of trephining, which are the principal surgical procedures adopted for the removal of offending substances from the great cavities of the human body.

My interest in the case was intensified by the fact that a case of pin-swallowing-occurring in a child of fourteen months old-was one of those for which I had to give advice on the first day on which I did resident surgeon's duty at the Richmond Hospital. But a short time before that occasion I had been reading Sir Thomas Watson's excellent advice for treatment of cases of swallowing foreign bodies, in which this brilliant lecturer did not hesitate to impress upon his pupils that average medical practice may, upon occasion, be sensibly improved even by the adoption of a hint offered by the traditional custom of a London pickpocket. I adopted his suggestions, and directed the anxious mother to feed her child for some time to come on the driest food it could well be got to swallow-dry, stiff, oatmeal porridge, hard-boiled eggs well rubbed up, and so on-and to let the bowels take care of themselves during the treatment. She went off apparently little satisfied with the very homely directions which she had received. She told me that she had heard that some doctors could give medicine that would "melt" the pin in her child's body. I assured her that such medicine, which was said by some to have been successfully employed in the days of the older alchymists, was entirely unknown to the profession in the present day, and dissuaded her as strongly as I could from the use of medicine by the 
mouth in any shape or form. Although but little reassured, she promised to follow my advice; and, on the eighth day from that date, she brought the missing pin to the hospital for my inspection. It had passed by the bowel that morning; it was very crooked, and had been embedded in a mass of hardened fæces. The intense gratitude with which she presented it to me forms one of the most vivid recollections of my professional experience, and certainly formed a striking contrast to the very limited degree of respect with which she had treated my advice on the day on which she consulted me.

A few years ago, a lady brought her child, an exceptionally bright and active girl, of a little less than two years old, to consult me about the nature and treatment of a lump which she had discovered on the inner side of the left thigh, when dressing the little one on the morning of her visit. I found a longitudinal tumour, nearly three inches in lengtl, the lower end of which was a little below the middle of the thigh, while its long axis was pretty accurately parallel with that of the femur. Lateral pressure did not seem to cause any pain, but pressure applied to the ends caused the child to wince, while there was no apparent alteration of the skin. The tumour, whatever it was, seemed to possess a shape regularily cylindrical, even to a degree of mathematical accuracy. I was a good deal puzzled as to its nature, for I knew of no neoplasm which would be likely to develop with so regular physical outlines. While trying to think out an opinion on the case, I continued to manipulate the mysterious lump, and suddenly noticed that on pressing at the upper end it moved a little downwards from its place. This effect naturally induced me to continue the pressure, and the movement continued, more and more easily as it passed downwards, while the lower end of the tumour became obviously pointed. Observing the latter change, I pressed 
the tissues firmly outwards against the inside of the femur, and drew the tumour downwards, so as to press against the skin so made tense. To my great surprise, the point of a needle suddenly emerged from the skir, after which, of course, a very little traction was necessary to extricate the rest of the domestic implement, which measured a little over two and a quarter inches in length. The anxious mother, who was present, screamed with intensity of emotion on seeing the needle brought to light; and at once recollected that about nine months before, when she had been playing with the child after sewing, and had been treating her baby, with maternal fondness, to some play with her thimbles, reels of cotton, \&c., the child had put a needle into her mouth. Something had, at that moment, turned the mother's attention to another corner of the nursery, and, when she again directed her looks to the baby in arms, the latter was evidently swallowing something, while the needle had disappeared. The child coughed spasmodically for a little, then commenced to cry, but almost immediately stopped. The mother was at first greatly frightened and very anxious, but as no other symptoms appeared, either then or at any subsequent date, she hoped that the needle had merely dropped out of sight somewhere, in the mysterious way in which needles so often do, and had not been swallowed at all. So long an interval of time had elapsed, that she had entirely forgotten all about the incident till she saw the needle extracted from her child's thigh. The point was somewhat blunted, and the whole body of the needle slightly eroded on the surface by its prolonged incarceration in the tissues and fluids of the child's body. The erosion was, however, but very superficial, and it was otherwise thoroughly preserved.

The pin which I have exhibited on the present occasion had been swallowed more than two days before I saw the 
child. The little one, after the first minute or two, had displayed no symptoms that could be referred to its presence in the body. She was then suffering from cough and diarrhœa, and had been receiving the domestic remedy of hippo. I had explained to the mother that, under the existing conditions, the hippo, cough, and diarrhoa were all very bad, as the first might produce sickness of stomach, which like the cough and diarrhœa, would have a decided tendency, by producing spasmodic contractions of the abdominal muscles, to press the pin through the wall of the digestive tube into some external cavity, organ, or vessel, where it might produce irreparable or even fatal mischief. I prescribed a mixture, the chief ingredients of which were liq. morph. hydrochlor., and potas. bromid., which had by the following day effectually checked both the cough and the diarrhœa. I impressed upon the child's mother that the great object of the treatment must be to keep the bowels confined, and to check all abdominal movements as far as possible, so that nature might have a fair chance of conveying the pin along the alimentary canal. I directed her to keep the child as quiet as possible, and mostly in the horizontal position; that all pressure upon the abdominal region should be most carefully avoided, and even, to a less extent on the chest wall; and, that when the child had to be raised, it should always be taken up by the arms. When it moved about, it was to do so quietly; and all rough play, especially such as involved sudden stooping, was strictly forbidden. I told the mother that no attempt whatever should be made to produce any movement of the bowels for a week at least, and that if she suffered from any colicky or wandering pains, the whole abdomen should be at once covered by a hot linseed poultice, which would give relief, and I would see afterwards what else could be done. The idea of keeping the child's bowels so long confined did not at all seem to reassure the anxious parents, but after the 
expenditure of a great deal of argumenl, I think $\mathbf{I}$ succee led in persuading them that it was the best thing that could be done under the circumstances - in fact, the least of all impending evils.

This treatment was continued for a week, the dry food regularly continued, and the least possible quantity of fluids administered. The bowels during that period mover twice: the first motion was a small quantity of hardened faces; the second, a large evacuation, and, as might be expected, extremely offensive. No pin, however, appeared.

I then directed that the treatment should be persisted in for another week, and told the child's parents that if the missing pin did not appear by the end of that period, this uncomfortable regime should be discontinued, and the ordinary mode of living again resumed. 'The bowels would clear out by enemas, and further developments awaited. The mother was greatly depressed by the idea of having her little one living such a life for another week, eating unenjoyable food, and suffering from the general heaviness and constant thirst, which necessarily accompanied the conditions. I comforted her as well as I could, and the treatment was carried out. The bowels were twice moved during the course of the week: masses of hardened scybalæ, of course, passed, and some of them were a good deal blood-stained, which did not tend to reassure the parents. At length, on the auspicious date of Halloween, about 9 p.m.- -and, accordingly, about 9 hours less than 16 days from the time that it was swallowed, the offending pin appeared. It had passe I with a large quantity of hardened freces, in which it, however, as far as I could learn, had appeared to be but partially imbedded. Observation as to this point, may, however, have been deceptive, as I had instructed the mother to get the child to sit on a cleai vessel containing at least a pint of clear water, so that the pin could be more readily found. 'There was no blood passed 
with this motion, and the child did not specially complain of pain.

The pin presents a certain amount of erosion on the surface so as to give it an aged appearance, although $I$ have been assured by the mother of the child that it was perfectly bright and new when swallowed. The advent of the pin made a happy Halloween in that household, and I have seldom heard so much gratitude expressed as I did on the 1st of November, when I visited there.

The case is, of course, one of the minor class, which, while fully qualified to produce great mental agony in private life, does not, nevertheless, figure with much dignity in the pages of a professional periodical or a scientific volume. I am fully sensible of this feature, and feel that $I$ owe an apology to the Fellows and Members of the Medical Section for bringing this small communication under their notice. It must, however, be noted that such cases, trivial as they may appeal when the result is fortunate, may attain a formidable degree of importance when fate has been less auspicious. Of twenty cases of the swallowing of pointed foreign bodies, which have been collected by Bernheim, and which had become entangled in the walls of the osophagus, and produced fatal results by ulceration, no less than fifteen had opened into some one of the great vessels in the neighbourhood, and so caused death by hæmorrhage. Of these no less than seven had penetrated the aorta, an accident which is easily explained by the close proximity of this great vessel to the gullet during a great part of the course of the latter. Of the others, the greater number had passed through the coats of the left common carotid artery, a fact which can also be readily understood by the close anatomical relation established by the deviation of the osophagus towards the left side, in the lower part of its cervical course. The others had pierced the right subclavian artery. A fatal case of perforation of the inferior 
thyroid artery at the level of the cricoid cartilage has been recorded by $M$. Pilate. A fatal case has been recorded by Mr. Andrew (Lancet, 1860) of a woman who had swallowed a fish-bone, which penetrated the osophagus and pericardium, and lodged in the interventricular septum of the heart, piercing the right coronary vein. The pericardium was found filled with blood, which had, of course, mechanically arrested the action of the heart.

Of the number of fatal accidents on record produced by the implication of other organs and cavities after the offending body had reached the stomach or intestine, there is practically no end, and I do not propose to attempt to tabulate them. Of those which have not immediately developed any serious lesions, some, by the mere irritation of their presence, have ultimately led to the same fatal result. Godelias and Mondiere have each recorded a case of cancerous stricture of the xsophagus attributable to the swallowing of a pin a long time before. In each case the pin was found embedded in the cancerous mass.

If we confine our attention to the swallowing of pins and needles only, it will he found, as indeed might be easily anticipated, that the great majority of recorded cases have occurred in the persons of females, children, and lunatics. Philosophic observers have declared before now that a special Providence appears to guard the members of at least two of these groups from the effects of accidents which might be deadly to less favoured specimens of the human family. All of the three cases to which I have referred in the present communication have occurred in female children-in each case exceptionally bright and intelligent members of their respective classes. As the result has also been in each case a gratifying one, I have thought, although with a considerable amount of diffidence, that the communication might possess some small interest for the Fellows and of Members the Royal Academy of Medicine in Ireland. 
The President said that eases of supposed pin-swallowing were not to be treated with contempt, but that the precautions laid down as to diet should be adopted. Some years ago a child was brought to him who was stated to have swallowed a pin. $\mathrm{He}$ found the pin in the child's mouth, the head in one tonsil and the point in the opposite. Three years ago a lady came to him complaining of pain in her throat. She said she had swallowed a large piece of ehicken. He drew up from her pharynx by means of a catheter a piece of bone.

DR. J. W. Moore said that he had treated a ease of a blind woman who swallowed a jagged piece of a mutton bone which had got into her soup. She vomited it after some retehing and coughing. He had a similar case of a county court judge who swallowed a piece of a chicken bone. Neither the jagged mutton bone nor the sharp chicken bone seemed to have inflicted any serious injury on the soft parts.

Dr. Parsons mentioned a case which occurred in Sir P. Dun's Hospital of a girl who swallowed a plate for holding false teeth. She was treated in the usual way, and in five or six days the plate was passed per rectum. She had no further symptoms. The plate had two very sharp hooks on it, and it is strange how it traversed the intestines without cansing injury.

Dr. Potter mentioned some cases of foreign bodies being swallowed. One was of a shawl pin. It lodged in the trachea and was extracted, except the head, which fell off and into one of the bronchi. It would be frequently coughed up into the trachea, but no further. The patient-a girl-left hospital, and her general health failed and she returned to hospital. An opening was made in the trachea and the head of the pin was conghed out of it. The girl completely regained her strength. He also saw a case of a pin removed from the neck; of a piece of bone removed from the pharynx per orem; and of a coin passed per rectum-all of which had been swallowed.

Dr. BdRGEss mentioned a case he saw of prolapse of the rectum, and in the prolapsed part he found a pin embedded. He had another case of a coin in the rectum, causing intense pain and drawing up of the anus. He removed it with his finger.

DK. DAwson recently saw a case in which about 8 oz. of hardware were removed from a lunatic's stomach. During life there had been no symptoms caused by their presence.

Dr. Knotr hriefly replied. 